\title{
The Impact of Timed Reading Activity on Iranian EFL learners Reading Speed, Comprehension, and Attitudes at Intermediate Level
}

\author{
Molood Mahdizadeh ${ }^{1 *}$, Naeemeh Aminafshar ${ }^{2}$ \\ ${ }^{\prime}$ MA Graduate, Department of Human Science, Islamic Azad University, Najafabad, Iran \\ ${ }^{2}$ MA Graduate - International Pardis University of Guilan, Iran \\ Corresponding Author: Molood Mahdizadeh, E-mail: moloodmahdizadeh@yahoo.com
}

\begin{tabular}{l} 
ARTICLE INFO \\
\hline Article history \\
Received: April 18, 2018 \\
Accepted: July 10, 2018 \\
Published: October 31, 2018 \\
Volume: 9 Issue: 5 \\
Advance access: August 2018 \\
\hline Conflicts of interest: None \\
Funding: None \\
\hline
\end{tabular}

Key words:

Timed Reading,

Reading Comprehension,

Reading Speed,

Reading Attitudes,

Learning

\begin{abstract}
Learning English is one of the most important activities around the world. Learning a language includes a number of skills and sub-skills. Reading is one of the skills of language learning, and it is the focus of the present study. Comprehension and speed are two main parts of the reading skill. The main aim of this study is to investigate the effects of timed reading activity on speed, comprehension and the attitudes of English learners regarding the use of timed reading activity. To this aim, a pre-test, a post-test and a questionnaire were used to gather data. 40 intermediate language learners participated in this study, and they were divided into two groups; experimental and control groups. Timed reading activity was employed as the treatment for the experimental group. The collected data revealed that the treatment had effect on the reading speed of the participants in the experimental group. Moreover, the data indicated that the timed reading activity was not highly effective to develop the reading comprehension skill of the language learners. And the results of the questionnaire indicated that a large number of the participants had positive attitude toward the timed reading activity.
\end{abstract}

\section{INTRODUCTION}

Reading can be considered as one of the most important skills that is now in more demand than any time around the world due to the vast amount of data in every specific area of research studies. It is the skill that has effect on the success in every academic area and academic disciplines. Learning to read is an important educational goal. For both children and adults, the ability to read lead to new worlds and opportunities. It makes us able to gain new knowledge, enjoy literature, and do everyday things that are parts of our modern life including reading novels, newspaper, instruction manuals, maps and so on. Fazeli (2010) mentioned the importance of reading in the civilized world. He believes that with the globalization and the technological changes of the world, reading has turned out to be an eminent skill for active participation and it is "the royal road to knowledge". (Fazeli, 2010, P.3)

Reading is one of the most crucial skills that plays a significant role in improving the readers' language proficiency, especially in a foreign language (FL) setting. Actually, English as a Foreign Language (EFL) learners, in contrast with English as a Second Language (ESL) learners, mostly rely on this skill to gain knowledge since the FL is rarely spoken outside the classroom. For most EFL/ESL students, reading is the most important part of their English course, which can help them to learn grammar (specially at the elementary levels), develop vocabulary knowledge and expand effective reading strategies. Surely, in foreign language learning, reading can be considered as a tool for getting information from different sources such as scientific and literary books and journals as well as the internet.

Chastain (1998) considered reading as a basic and complementary skill in language learning. She believed ESL students should learn to read as soon as possible. Actually for most EFL learners reading is the only source of gaining knowledge of the FL since they may hardly have access to the native speakers and FL is not spoken outside the classroom.

By comparing first language (L1) and second language (L2) reading, one eminent difference is the rate of reading. For many EFL learners, reading in L2 is a slow process with a lot of repetitions and pauses which can never represent fluent reading even if the reader completely comprehends the text.

Many Iranian EFL learners suffer the same problem when they try reading in English. Due to their slow reading speed, they may not totally enjoy reading in a foreign language. 
And as Nuttal (1996) mentioned, "speed, enjoyment, and comprehension are closely linked with one another". Thus, the current study intends to show the impact of timed reading activity on the reading speed and the comprehension of Iranian EFL learners at intermediate level. Also, the learners' attitudes toward the timed reading activity are investigated.

\section{REVIEW OF LITERATURE}

Due to the reading's widespread influences, reading competency is an essential concern in today's EFL instructional contexts (Fuchs, Fuchs, Hosp \& Jenkins, 2001). Fluency is usually considered as a major component of reading competency and a key component to successful reading program (Wolf \& Katzir-Cohen, 2001). Reading fluency is gaining new recognition as a crucial element in both ESL and EFL contexts.

According to the National Reading Panel, fluency is the ability to read a text quickly and with a proper expression. Fluency plays an important role in becoming a good reader. For fluent readers, recognizing the words and comprehending them occur at the same time. Fluency is defined as "the ability to read connected text rapidly, smoothly, effortlessly, and automatically with little attention to the mechanics of reading, such as decoding" (Meyer and Felton, 1999, p. 284). While this definition seems simple, Hall (2006) mentioned that there is no specific accepted definition for it, despite the increasing recognition of the importance of fluency in reading instruction. Miller (2007) pointed out that fluency is a mixture of several factors: speed, prosody or phrasing, expression, intonation, pacing, and comprehension. Rasinski (2004) suggests that we need to consider accuracy in word recognition, automaticity in word recognition and interpretive and meaningful reading.

Reading fluency is described as "the ability to read rapidly with ease and accuracy and to read with appropriate expression and phrasing. It involves a long incremental process and text comprehension is the expected outcome." (Grabe, 2009, P. 291) Developing fluency in FL reading has become a crucial issue for pedagogy in L2 contexts (Chung, 2010).

Timed reading is a fluency learning activity which makes readers read a text under time pressure to read faster than their usual speed of reading. Chang (2010, p. 287) pointed out that "timed reading involves having students read under time pressure, the purpose of which is to improve reading speed to an optimal rate that supports comprehension rather than developing speedy readers."

A similar research study was conducted by Chang (2010). She aimed to develop reading fluency. She employed a 13week timed reading activity in order to improve the learners' reading speed. 84 participants were divided into the experimental and the control groups. A test was used to gather data regarding the speed and the comprehension of the students. A final written report by the participants showed their perception regarding the timed reading activity. The data revealed that the reading speed and the reading comprehension of the participants of the experimental group were increased. "Students who did the timed reading activity became more confident in their reading and were impressed with the amount of the reading they had done without the teachers' guidance." (Chang, 2010, 284)

The context where the research study is conducted can be considered as vital factor, and it may cause the study to result in different outcomes. Therefore, the current study intends to show the impact of timed reading activity on reading speed and comprehension of Iranian EFL learners at intermediate level. Furthermore, it is intended to explore the students' attitudes regarding the use of timed reading activity at the end of the course activity.

\section{THE STUDY}

Adopting a qualitative/quantitative method can provide the research with a complement picture of the issue at study. Accordingly, following the mixed methods approach, this study adopted both qualitative and quantitative (pre-tests, post-test and open-ended questionnaire) techniques to provide description of the improvement of reading in the target language and the students' attitudes regarding using timed reading activity.

\section{Participants, Instruments and Procedure}

The participants of the study consist of the students (including male and female) of an Institute for Higher Education in Tonekabon city in Iran. In order to ensure the homogeneity of the students, an Oxford Placement Test (OPT) was assigned, and 40 Intermediate level students were selected. They were randomly divided into two groups: an experimental group and a control group. Each group consisted of 20 students. The experimental group received timed reading activity as a treatment. Twenty passages from Asian and Pacific Speed Readings for ESL Learners were chosen for timed reading activity. The control group read the same passages but without any time pressure. They read and answered reading comprehension questions.

To access the effect of the treatment on the participants' reading speed and reading comprehension, a pre-test was administered to the participants of both groups. The pretest's results show the participants' level of reading speed and comprehension. One passage of Asian and Pacific Speed Readings for ESL Learners was chosen as pre-test. Then a post-test was administered to both groups; it was supposed to show the probable effects of the treatment on the experimental group. One passage of Asian and Pacific Speed Readings for ESL Learners was considered as post-test. It is also worth mention that ten comprehension questions were followed by each reading passages.

An open-ended questionnaire measured the students' attitudes regarding the use of timed reading activity. The questionnaire was given to the students of the experimental group at the final sessions of their course. The open-ended questionnaire was employed to better understand the students' experience during the timed reading activity. The qualitative side of the open-ended questionnaire allowed the researcher adds an extra dimension to the research.

To examine the influence of timed reading activity on the reading speed and the reading comprehension of Iranian 
EFL learners, twenty passages from Asian and Pacific Speed Readings for ESL learners were chosen for both experimental and control group. Asian and Pacific Speed Readings for ESL Learners is a re-editing of Quinn and Nation's (1974) Speed Reading: A Course for Learners of English. The passages contain twenty 550 word readings, each with ten comprehension questions. The topics of the reading are mostly related to Asia and the Pacific and are written within the 1000 most frequently used words of English (West, 1953).

\section{RESULTS AND DISCUSSION}

The results of the pre-test indicated that the two groups are not significantly different regarding the reading speed. When the treatment (i.e. the timed reading activity) was totally conducted, all of the participants took a post-test. The aim of the post-test was to investigate the progress of the learners in reading speed and comprehension skill in order to discover whether this type of activity is more beneficial for the language learners.

\section{Results of the Post-test Scores}

T-test was run on the reading speed of the students in the post-test. Independent T-test was employed to compare a specific variable among two unmatched groups. The following Table 4.1 provides simple summaries about the basic features of the data.

Table 4.1 represents the descriptive statistics for the two groups i.e. the experimental group and the control group. The means average of the two groups seem to be different, 103 for the control group and 122 for the experimental group. As far as random sampling had been done, this difference could not be attributed to chance or other factors involved in the testing issues such as environment issues or scoring issues; therefore, such a discrepancy can be attributed to the effect of the treatment. The following Table 4.2 takes into account further analysis to show the output of the T-test and whether there is a statistically significant difference between the two groups regarding the reading speed.

As shown in the table, the significance level is 0.00 ( $p=.000)$, which is below 0.05 . $(0.00<0.05)$; therefore, there is a statistically significant difference in the post-test results of the two groups. It can be concluded that the treatment, i.e. timed reading activity, had effect on the reading speed of the participants in the experimental group. Thus, there is a significant difference between the two groups, and the timed reading activity can be considered as an effective activity for improving the reading speed.

For a better understanding of the result of the analysis, a visual representation of the results is presented in Figure 4.1 which is a line chart of the relationship among the groups.

The line chart 4.1 provides useful facts. It indicates a comparison of the reading speed of the two groups both before and after taking the course. The difference of both pre-test and post-test scores are significant, and this discrepancy can be easily seen in chart. The line which represents the experimental group tends to be rising; it indicates that the experimental group proved to be more successful regarding the reading speed.

\section{The Comprehension Scores of the Post-test}

As mentioned before, ten comprehension questions were followed by each reading passages. And the final score of the

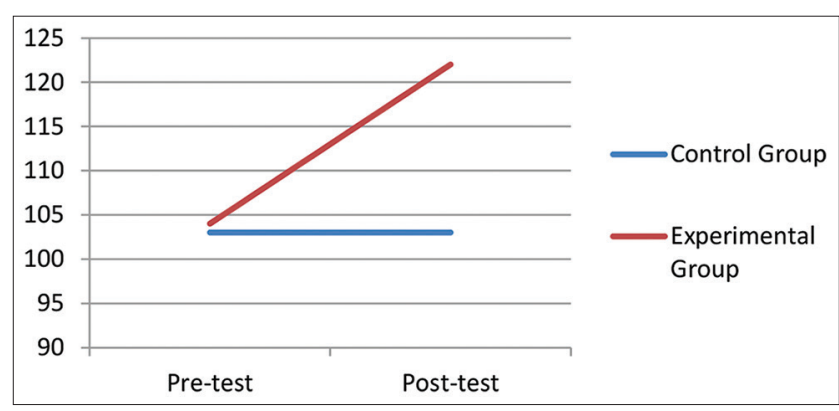

Figure 4.1. The line chart for the reading speed of the two groups

Table 4.1. Descriptive statistics for the reading speed of the post-test

\begin{tabular}{llllcr}
\hline & Groups & N & Mean & Standard deviation & Standard error mean \\
\hline Readingspeed & Control group & 20 & 103.10 & 8.422 & 1.883 \\
& Experimental group & 20 & 122.15 & 15.135 & 3.384 \\
\hline
\end{tabular}

Table 4.2. T-test of the post-test reading speed

\begin{tabular}{|c|c|c|c|c|c|c|c|c|c|}
\hline & \multicolumn{2}{|c|}{$\begin{array}{l}\text { Levene's test } \\
\text { for equality } \\
\text { of variances }\end{array}$} & \multicolumn{7}{|c|}{ T-test for equality of means } \\
\hline & \multirow[t]{2}{*}{$\mathbf{F}$} & \multirow[t]{2}{*}{ Sig. } & \multirow[t]{2}{*}{$\mathbf{t}$} & \multirow[t]{2}{*}{ df } & \multirow[t]{2}{*}{ Sig. (2-tailed) } & \multirow[t]{2}{*}{$\begin{array}{c}\text { Mean } \\
\text { difference }\end{array}$} & \multirow[t]{2}{*}{$\begin{array}{l}\text { Standard } \\
\text { error } \\
\text { difference }\end{array}$} & \multicolumn{2}{|c|}{$\begin{array}{l}\text { 95\% Confidence } \\
\text { interval of the } \\
\text { difference }\end{array}$} \\
\hline & & & & & & & & Lower & Upper \\
\hline \multicolumn{10}{|l|}{ Reading speed } \\
\hline $\begin{array}{l}\text { Equal variances } \\
\text { assumed }\end{array}$ & 7.156 & 0.011 & -4.919 & 38 & 0.000 & -19.050 & 3.873 & -26.891 & -11.209 \\
\hline $\begin{array}{l}\text { Equal variances not } \\
\text { assumed }\end{array}$ & & & -4.919 & 29.737 & 0.000 & -19.050 & 3.873 & -26.963 & -11.137 \\
\hline
\end{tabular}


comprehension questions is considered out of 10 . The aim of analyzing the comprehension scores of the post-test was to discover whether the timed reading activity of the experimental group had impact on their level of reading comprehension. Therefore, the comprehension scores of the control group and the experimental group were compared together.

Table 4.3 represents the descriptive statistics for the two groups regarding their comprehension scores of the post-test.

As shown in the table, the mean averages of the comprehension scores are totally different; they are 6.80 for control group and 7.10 for the experimental group. The students of the experimental group, who received the timed reading treatment, improved their reading comprehension skill just a little more than the students of the control group. The scores have been compared to the pre-test score and to summarize the results by percentage, the participants of the control group almost got 4\% improvement in reading comprehension. And the participants of the experimental group almost got $10 \%$ improvement in reading comprehension. This difference seems to be significant; however, further analysis is needed to investigate whether there is a significant difference between the control group and the experimental group regarding reading comprehension.

The result of the Independent Sample T-test could be taken into consideration to further analyze the comparison of the two groups.

The value of $t$ at the level of 38 degree of freedom is significant that is the value of $t$ is higher than 0.05 ( $0.42 \mathrm{sig}$ $>0.05)$. This reveals that the two groups are not significantly different regarding the comprehension scores. This result indicates that timed reading activity is not highly effective to develop the reading comprehension skill of language learners. Therefore, there is no significant difference between the two groups, and timed reading activity cannot be considered as a highly effective activity for improving the reading comprehension.
For a better understanding of the result of the analysis, a visual representation of the results is presented in Figure 4.2 as a clustered bar chart of the relationship among the groups.

As illustrated in the graph, the comprehension scores are plotted on the $\mathrm{x}$ axis, and the two groups are differentiated by using two colors. The numbers of students are plotted on the $y$ axis. As can be seen, the experimental groups received some higher scores which confirm the fact that this group became more successful in this study; however, the difference between the two groups is not significant.

To summarize the data regarding the comprehension scores of both the pre-test and the post-test, the following Figure 4.3 is presented.

The chart 4.3 provides useful facts. It indicates a comparison of the comprehension scores of the two groups both before and after the course. As mentioned before, the difference between pre-test and post-test scores are not significant; however, the reading course was effective for both groups to improve their reading comprehension skill.

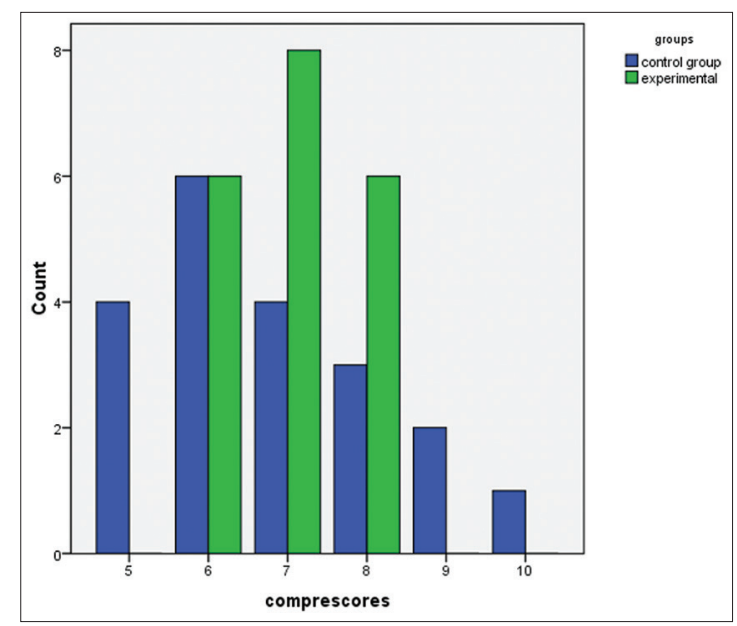

Figure 4.2. The clustered bar chart of the reading comprehension scores of the post-test

Table 4.3. Descriptive statistics for the comprehension scores of the post-test

\begin{tabular}{llcccr}
\hline & Groups & N & Mean & Standard deviation & Standard error mean \\
\hline Comprescores & Control group & 20 & 6.80 & 1.473 & 0.329 \\
& Experimental & 20 & 7.10 & 0.788 & 0.176 \\
\hline
\end{tabular}

Table 4.4. T-test of the post-test reading comprehension

\begin{tabular}{|c|c|c|c|c|c|c|c|c|c|}
\hline \multicolumn{10}{|c|}{ Independent samples test } \\
\hline & \multicolumn{2}{|c|}{$\begin{array}{l}\text { Levene's test } \\
\text { for equality of } \\
\text { variances }\end{array}$} & \multicolumn{7}{|c|}{ T-test for equality of means } \\
\hline & \multirow[t]{2}{*}{$\mathbf{F}$} & \multirow[t]{2}{*}{ Sig. } & \multirow[t]{2}{*}{$\mathbf{t}$} & \multirow[t]{2}{*}{ df } & \multirow[t]{2}{*}{ Sig. (2-tailed) } & \multirow[t]{2}{*}{$\begin{array}{c}\text { Mean } \\
\text { difference }\end{array}$} & \multirow[t]{2}{*}{$\begin{array}{l}\text { Standard } \\
\text { error } \\
\text { difference }\end{array}$} & \multicolumn{2}{|c|}{$\begin{array}{l}\text { 95\% Confidence } \\
\text { interval of the } \\
\text { difference }\end{array}$} \\
\hline & & & & & & & & Lower & Upper \\
\hline \multicolumn{10}{|l|}{ Compare scores } \\
\hline $\begin{array}{l}\text { Equal variances } \\
\text { assumed }\end{array}$ & 7.592 & 0.009 & -0.803 & 38 & 0.427 & -0.300 & 0.373 & -1.056 & 0.456 \\
\hline $\begin{array}{l}\text { Equal variances } \\
\text { not assumed }\end{array}$ & & & -0.803 & 29.058 & 0.428 & -0.300 & 0.373 & -1.064 & 0.464 \\
\hline
\end{tabular}




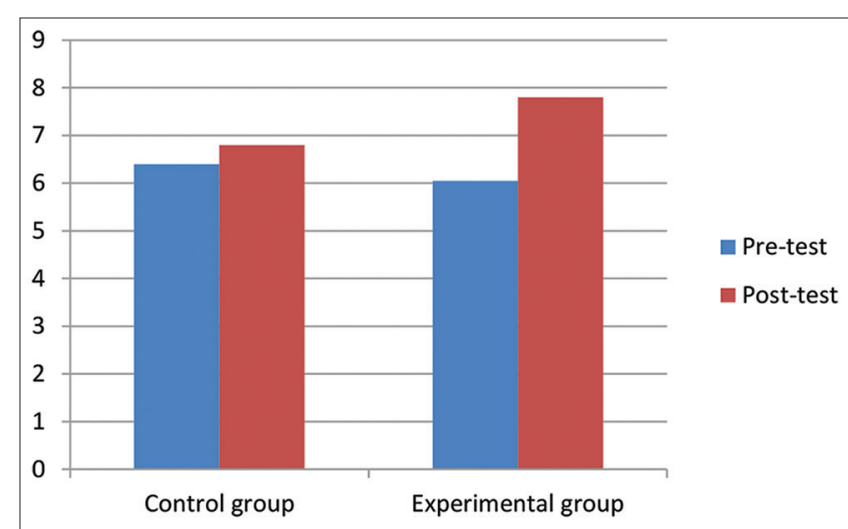

Figure 4.3. The chart of the comprehension scores of the pre-test and the post-test

\section{Open-ended Questionnaire}

An open-ended questionnaire was used to determine the participants' attitude regarding the use of timed reading activity. All of the 20 participants of the experimental group filled the questionnaire at the end of the threemonth course. The researcher analyzed the anonymous filled questionnaires to gather data regarding the students' opinions. As mentioned before, this part of the research is analyzed qualitatively. To this aim, each question of the questionnaire is pointed out, and the students' answers are mentioned in summary. The questionnaire items were validated in the pilot study. The results of the questionnaire are presented as follows.

\section{How effective timed reading activity is to improve your reading speed? What are the possible advantages and disadvantages?}

The statistics indicated that the reading speed of the experimental group was improved. Now, let's have a look at the students' opinions regarding this issue. Nearly all of the students reported that their reading speed had improved. Most of them declared that now they are able to read English passages faster than before.

Regarding the possible advantages, 16 out of 20 students also mentioned that timed reading made them concentrate better. 15 students pointed out that their confidence in reading was increased since they did not believe that they could read so many passages on their own. 14 students mentioned that now they are encouraged to read not only their textbooks but also some other books, e.g. novels and short stories, since they are able to read fast enough.

As for the possible disadvantages, 14 students mentioned that at the beginning of the course, timed reading activity increased their anxiety level since they felt the pressure of time. However, as the time went by, their anxiety disappeared since the students got used to this activity. Generally, it can be concluded that timed reading activity has played a significant role in improving the reading speed of the EFL language learners.

\section{How effective timed reading activity is to improve your reading comprehension? What are the possible advantages and disadvantages?}

The statistics showed only a slight difference between the experimental group and the control group regarding the comprehension scores. Now let's have a look at the students' opinions regarding this issue. Nearly all of the students believed that timed reading activity had no special effect on improving their reading comprehension. They mentioned that reading comprehension can be improved by increasing their vocabulary knowledge rather than reading fast.

Nearly all of the students mentioned that the only advantage of fast reading can be related to the concept of 'time'. In other words, they believed that when they can read fast, they can understand the passage soon and also finish the comprehension questions sooner than before. Therefore, when there is a pressure of time, they can act better.

As for the disadvantages, most of the students pointed out that when the passage is hard, and it contains lots of new words, fast reading may cause some problems for reading comprehension. Thus, they may be forced to reread some parts in order to comprehend the passage. Generally, it can be considered that timed reading has effect on the time that is spent to comprehend a passage, and it has no special impact on improving the comprehension skill.

\section{How difficult is to use timed reading activity?}

As mentioned, some of the students pointed out that at the first sessions of the course, it was a bit difficult for them to learn how to do timed reading activity, but later using it became normal for them. In other words, they had no difficulty or problem in timed reading. As mentioned before, another difficulty was related to the stressful moments that some students suffered during the first sessions. However, this feeling disappeared soon, and the students learned how to cope with the timed reading activity. Moreover, 9 students declared that the reading passages were not so easy to comprehend.

Generally, it can be concluded that the main difficulty which is directly related to the timed reading activity is anxiety. This is a feeling which can be decreased by providing positive and friendly atmosphere in classroom.

\section{Do you have any suggestions for future timed reading courses?}

Nearly all of the students mentioned that they wished they were divided in groups, and there was a type of privilege or prize for the group that read faster and had fewer mistakes in answering the questions. 10 students pointed out that they preferred they would choose at least some of the passages which they read during the course. 12 students declared that during a reading course, it would be better if once or twice the teacher bring a hard passage to challenge the students. These statements are worthwhile, and they can help teachers to modify their techniques for a reading course. 


\section{CONCLUSION}

In this study, the effect of using timed reading activity on the reading speed and the reading comprehension was investigated by using a pre-test and a post-test. Moreover, the participants' attitudes of the experimental group were investigated by using an open-ended questionnaire. Let's briefly mention the final results of the present study.

Timed reading activity was a highly significant treatment for increasing the reading speed of the language learners of this study. Moreover, this type of activity made the learners become more confident and independent. Therefore, it is concluded that this type of activity can be employed specially for enhancing the reading speed of language learners. It can be realized that timed reading activity is also beneficial for those students who are supposed to take a standardized test of English language proficiency, e.g. TOEFL or IELTS, and also for those students who wants to take less important tests, e.g. their school exams or any type of entrance exam. We all know that fast reading is a valuable ability which is useful not only for language learners but also for all of the people since nowadays new technologies are developed and improved to save our time and energy; thus, being a fast reader can be considered as a kind of gift for everyone in this world.

Timed reading activity proved to be a treatment which is not highly influential for improving the reading comprehension of the language learners of this study. In other words, the ability of reading fast proved to be almost ineffective on increasing the level of reading comprehension. Reading comprehension is also a valuable ability especially for language learners. Therefore, teachers or curriculum designers need to employ other remedial techniques to improve the language learners' comprehension.

The results of the questionnaire indicated that a large number of the participants had positive attitude toward the timed reading activity. They enjoyed being able to read faster. However, they mentioned that their reading comprehension cannot be improved by this activity. They suggested having different tasks for increasing vocabulary knowledge in order to comprehend a reading passage better. Moreover, slight level of anxiety was reported, but it disappeared when the participants became more familiar with the activity. To sum up, timed reading activity has a number of advantages in improving the reading skill. However, other types of activities are needed to improve the learners' reading comprehension.

It is also worth mention that the result of the present study is in contrast with the similar study which was conducted by Chang (2010). One reason of such discrepancy can be the role of context. However, further research studies are needed to be conducted to reach to a consistent outcome.

\section{REFERENCES}

Chang, A. (2010). The effect of a timed reading activity on EFL learners. Reading in a Foreign Language, 22(2), 284-303.

Chastain, K. (1998). Developing second language skills $\left(2^{\text {nd }} E d\right.$. $)$. Chicago: Harcourt Brace Publishers.

Chung, M. (2010). The effect of a speed reading course: A replication. Asian Journal of English Language Teaching, 20, 95-116.

Fazeli, H. (2010). Some Gaps in the Current Studies of Reading in Second/Foreign Language Learning. Language In India. 10, 373-385.

Fuchs, L. S., Fuchs, D., Hosp, M. K., \& Jenkins, J. R. (2001). Oral reading fluency as an indicator of reading competence: A theoretical, empirical, and historical analysis. Scientific Studies of Reading, 5, 239-256.

Grabe, W. (2009). Reading in a second language: Moving from theory to practice. New York: Cambridge University Press.

Hall, S. L. (2006). I've DIBEL'd, now what?. Longmont, CO: Sorpis West.

Meyer, M.S., Felton, R.H. (1999). Repeated reading to enhance fluency: Old approaches and new directions. Annals of Dyslexia, 49, 283-306.

Miller, D. (2007). Making the most of small groups: Differentiation for all. Ontario, Canada: Pembroke.

Nuttall, C. (1996). Teaching Reading Skills in a foreign language. Oxford: Heinemann.

Quinn, E., \& Nation, P. (1974). Speed reading. Wellington, New Zealand: Victoria University Book centre.

Rasinski, T. V. (2004). Creating fluent readers. Educational Leadership. March, 46-50.

West, M. (1953). A general service list of English words. London: Longman.

Wolf, M., \& Katzir-Cohen, T. (2001). Reading Fluency and Its Intervention. Scientific Studies of Reading, 5, 211-239. 